IJPP 2009, 17: 373-376 (C) 2009 The Authors Received May 7, 2009 Accepted August 4, 2009 DOI 10.1211/ijpp/17.06.0010 ISSN 0961-7671

\section{Time and motion study for pharmacists' activities in a geriatric hospital}

\author{
Francesca Wirth, Lilian M. Azzopardi, Marise Gauci, \\ Maurice Zarb Adami and Anthony Serracino-Inglott \\ Department of Pharmacy, University of Malta, Msida, Malta
}

\begin{abstract}
Objectives This study aimed to identify and quantify activities undertaken by pharmacists in a geriatric hospital.

Methods A data collection form was developed, validated and tested for applicability and practicality. Pharmacist activities were organised into three categories: Clinical, Administration and Others. Clinical activities incorporated patient discharge, patient admission, checking the ward controlled drugs record book, emergency trolley and patient medication trolley, prescription monitoring, ward round, discussion with health care professionals, and other professional activities; Administration activities included checking the ward medication stock and medication order; Others included break and inactive time. Observers conducted 6000 min of direct observation using a time and motion technique and observed the work activities of three pharmacists on three wards. Data were analysed using Microsoft Excel 2007 and SPSS version 16.0. Descriptive statistics were carried out. Key findings The time dedicated to Clinical activities was $3636 \mathrm{~min}(60.60 \%)$, Administration activities $1646 \mathrm{~min}(27.43 \%)$ and Others $718 \mathrm{~min}(11.97 \%)$. When considering total time in minutes for Clinical and Administration activities, ward round (1348 $\mathrm{min})$, medication order (1255 $\mathrm{min})$, patient discharge $(723 \mathrm{~min})$ and prescription monitoring $(562 \mathrm{~min})$ occupied most of the pharmacists' time. Ward round activities were subdivided into: patient profiling (545 $\mathrm{min})$, actual ward round $(668 \mathrm{~min})$ and conference (135 min).
\end{abstract}

Conclusions The time and motion study indicated that the pharmacists' time is mainly allocated to clinical activities. However, there is still a large proportion of time taken up by administrative activities, which can be conducted by non-pharmacist personnel, allowing more time to be directed to patient care.

Keywords clinical pharmacy; direct observation; time and motion study; ward round

\section{Introduction}

Studies to describe and evaluate impact of activities undertaken by clinical pharmacists have been carried out. ${ }^{[1-4]}$ However, time and motion studies by direct observation to quantify the time taken for clinical pharmacy interventions are less well documented. ${ }^{[5]}$ Such studies may be undertaken to identify activities carried out by pharmacists in the community ${ }^{[6-9]}$ and hospital setting. ${ }^{[4,10]}$ The objective of this study was to carry out a time and motion study by direct observation to identify and quantify activities undertaken by pharmacists at Zammit Clapp Hospital (ZCH).

\section{Methods}

$\mathrm{ZCH}$ is a 60-bed hospital specialising in geriatric medicine. The Pharmacy Department staff consisted of three pharmacists each responsible for a ward. One ward consists of 10 patient beds whereas the other two wards each have 25 patient beds. Ward rounds are held once a week on each ward. A patient profile is prepared by the pharmacist upon admission and is updated daily during the prescription monitoring process. Using the profile, the pharmacist identifies pharmaceutical care issues to be discussed with the other health care professionals in the team during the ward round. The conference is held after the ward round during which the patient is reviewed by the team in an office setting. Progress of the patients
Correspondence: Francesca Wirth, Department of Pharmacy, University of Malta, Msida MSD1080, Malta. E-mail: francesca.wirth@um.edu.mt 
is discussed and discharges are planned. Attendance by the pharmacist is subject to pharmacist availability.

Consent to carry out the study was obtained from the ZCH Research Committee. The observers (FW, MM (see Acknowledgement $\left.{ }^{\mathrm{a}}\right)$ ) attended $\mathrm{ZCH}$ for $1200 \mathrm{~min}$ of preorientation visits on 5 days to observe the work activities of the pharmacists. A list of these activities was compiled and a data collection form was developed to document the observations. Face and content validity testing of the form was undertaken by the pharmacists at $\mathrm{ZCH}$ and a pharmacist in academia. Amendments suggested were implemented.

The final data collection form organised pharmacist activities into three categories: Clinical (must be performed by a pharmacist), Administration (may be performed by competent non-pharmacist personnel under pharmacist supervision), and Others (break time and inactive time). Clinical activities incorporated patient discharge, patient admission, checking the ward controlled drugs record book, emergency trolley and patient medication trolley, prescription monitoring, ward round, discussion with health care professionals, and other professional activities; whereas Administration activities included checking the ward medication stock and medication order (Tables 1 and 2). Checking the patient medication trolley was classified as Clinical as the pharmacist checks the patient medication drawer in the trolley against the patient ward prescription sheet to review patient drug therapy and minimise risk of medication errors. Emergency trolley checking was classified as Clinical since according to hospital policy it must be checked and sealed by a pharmacist and every transaction related to this trolley should be documented.

A pilot study was carried out to test the practicality of the data collection form and the applicability of the classification system. The observers conducted 1200 min of observation, observing the work activities of the three pharmacists on the wards continuously on 3 days. The time taken for each activity observed was recorded under the correct division in the data collection form.

No major changes to the data collection form were required after this pilot and these 1200 min were included in the total 6000 min of observation. Data were analysed using Microsoft Excel 2007 and SPSS version 16.0 and descriptive statistics carried out.

Table 1 Descriptive statistics for Clinical activities

\begin{tabular}{|c|c|c|c|c|c|c|}
\hline \multirow[t]{2}{*}{ Divisions/sub-divisions of data collection form } & \multirow[t]{2}{*}{$n$} & \multirow[t]{2}{*}{ Total time (min) } & \multirow[t]{2}{*}{ Range (min) } & \multicolumn{3}{|c|}{ Percentiles (min) } \\
\hline & & & & 25 & 50 & 75 \\
\hline \multicolumn{7}{|l|}{ Patient discharge } \\
\hline Checking and printing discharge letter & 14 & 66 & $2-10$ & 3.00 & 3.00 & 7.00 \\
\hline Checking applications for free medications/medical devices & 9 & 93 & $3-25$ & 5.50 & 9.00 & 13.50 \\
\hline Preparation of discharge medication information sheet & 10 & 219 & 4-37 & 17.50 & 20.50 & 31.25 \\
\hline Preparation of discharge medications & 15 & 142 & $3-19$ & 5.00 & 8.00 & 15.00 \\
\hline Discharge counselling to patient and/or carer & 16 & 203 & $5-26$ & 8.25 & 10.00 & 18.50 \\
\hline \multicolumn{7}{|l|}{ Patient admission } \\
\hline $\begin{array}{l}\text { Checking drawers in patient medication trolley with ward prescription } \\
\text { sheet and labelling medication containers }\end{array}$ & 16 & 87 & $2-15$ & 3.00 & 5.00 & 6.00 \\
\hline Initial filling of patient profiles & 16 & 150 & $4-22$ & 5.25 & 8.00 & 11.50 \\
\hline \multicolumn{7}{|l|}{ Checking ward controlled drugs and trolleys } \\
\hline Ward controlled drugs record book & 22 & 67 & $1-6$ & 2.00 & 3.00 & 4.00 \\
\hline Emergency trolley & 22 & 36 & $0.33-10$ & 0.33 & 0.50 & 0.85 \\
\hline Patient medication trolley & 22 & 252 & $4-22$ & 7.00 & 10.00 & 15.25 \\
\hline \multicolumn{7}{|l|}{ Prescription monitoring } \\
\hline $\begin{array}{l}\text { Checking medication amendments with ward prescription sheet and } \\
\text { updating patient profiles }\end{array}$ & 22 & 562 & $12-45$ & 20.00 & 25.00 & 30.25 \\
\hline \multicolumn{7}{|l|}{ Ward round } \\
\hline Detailed patient profiling & 11 & 545 & $10-100$ & 35.00 & 50.00 & 60.00 \\
\hline Actual ward round & 5 & 668 & $60-170$ & 97.50 & 150.00 & 161.50 \\
\hline Conference & 2 & 135 & $35,100^{\mathrm{a}}$ & 35.00 & 67.50 & 100.00 \\
\hline \multicolumn{7}{|l|}{ Discussion with health care professionals } \\
\hline With pharmacist & 9 & 85 & $2-25$ & 3.50 & 7.00 & 13.50 \\
\hline With nurse & 17 & 87 & $2-12$ & 3.00 & 5.00 & 6.00 \\
\hline With doctor & 15 & 106 & $2-20$ & 4.00 & 6.00 & 8.00 \\
\hline Other health care professionals & 2 & 10 & $3,7^{\mathrm{a}}$ & 3.00 & 5.00 & 7.00 \\
\hline \multicolumn{7}{|l|}{ Other professional activities } \\
\hline Discussion with patient carer after discharge & 4 & 41 & $5-16$ & 5.50 & 10.00 & 15.25 \\
\hline Student demonstrations/teaching & 1 & 55 & $55^{\mathrm{a}}$ & 55.00 & 55.00 & 55.00 \\
\hline Preparation of medications for hospital staff & 2 & 11 & $2,9^{\mathrm{a}}$ & 2.00 & 5.50 & 9.00 \\
\hline Dispensing of prescriptions for day hospital & 1 & 16 & $16^{\mathrm{a}}$ & 16.00 & 16.00 & 16.00 \\
\hline
\end{tabular}


Table 2 Descriptive statistics for Administration activities

\begin{tabular}{|c|c|c|c|c|c|c|}
\hline \multirow[t]{2}{*}{ Divisions/sub-divisions of data collection form } & \multirow[t]{2}{*}{$n$} & \multirow[t]{2}{*}{ Total time (min) } & \multirow[t]{2}{*}{ Range (min) } & \multicolumn{3}{|c|}{ Percentiles (min) } \\
\hline & & & & 25 & 50 & 75 \\
\hline \multicolumn{7}{|l|}{ Checking ward medication stock } \\
\hline Main medications cabinet & 22 & 278 & $4-25$ & 9.75 & 11.50 & 15.50 \\
\hline Injections cabinet & 22 & 72 & $1-5.5$ & 2.00 & 3.50 & 5.00 \\
\hline Refrigerator & 22 & 27 & $0.33-2.33$ & 1.00 & 1.00 & 1.25 \\
\hline Nutrition supplements & 22 & 14 & $0.33-1.08$ & 0.50 & 0.67 & 0.71 \\
\hline \multicolumn{7}{|l|}{ Medication order } \\
\hline Preparation of medications/medical devices for ward & 22 & 403 & $5-50$ & 10.00 & 17.00 & 23.00 \\
\hline Delivery of medications to ward & 22 & 254 & $5-23$ & 8.75 & 10.00 & 15.00 \\
\hline Organisation of bulk orders for pharmacy main store & 9 & 196 & $9-35$ & 12.00 & 20.00 & 31.00 \\
\hline Recording orders in written forms & 22 & 97 & $2-12$ & 3.00 & 3.50 & 5.00 \\
\hline Entry of forms into computer system & 8 & 305 & $15-60$ & 25.00 & 37.50 & 53.75 \\
\hline
\end{tabular}

\section{Results}

The $6000 \mathrm{~min}$ of observation were divided into: $3636 \mathrm{~min}$ (60.60\%) for Clinical activities, $1646 \mathrm{~min}(27.43 \%)$ for Administration activities, and 718 min (11.97\%) for activities in the Others category. For the Clinical and Administration activities, ward round (1348 $\mathrm{min} ; 22.47 \%)$, medication order (1255 min; 20.92\%), patient discharge (723 min; 12.05\%), prescription monitoring (562 min; $9.37 \%$ ) and checking of ward medication stock (391 min; $6.52 \%$ ) were predominant.

Tables 1 and 2 show the sample size $(n)$, total time, range and percentiles (25th, 50th and 75th) for each activity subdivision.

\section{Discussion}

The time and motion study provided information on workload distribution of pharmacists at $\mathrm{ZCH}$ and indicated that clinical activities particularly ward round, prescription monitoring and patient discharge activities occupied most of the pharmacists' time. This study gives an insight into the work distribution of pharmacists and uses a direct observation method. The findings do not rely on reporting by pharmacists but rather on how the time is actually spent. The weaknesses of the study are that the observation was carried out over $100 \mathrm{~h}$ for the three pharmacists, which could have been extended. Also, the impact of the clinical activities on patient outcome was not assessed. The time and motion study technique adopted for the study required an observer observing the pharmacist continuously. This has two drawbacks: it is time-consuming and could influence the pharmacist's work patterns.

In a 3-month self-reporting study carried out by Montazeri and $\operatorname{Cook}^{[2]}$ in a 15-bed medical-surgical intensive care unit of a Canadian hospital, most of the clinical pharmacist's time was spent on interventions, intensive-care-unit rounds and profile review. In another study by Robinson and Stump ${ }^{[3]}$ carried out by self-reporting over 2 weeks in four decentralised practice sites in a US hospital, clinical pharmacists spent the largest percentage of their time on profile review. The results from this local study are comparable to these reports since most of the pharmacists' time at $\mathrm{ZCH}$ was taken up by activities involving reviewing and updating patient profiles.

In the study by Robinson and Stump, ${ }^{[3]}$ other prominent activities were the retrieval of laboratory data, therapeutic drug monitoring and pharmacokinetic calculations. These activities were not included as separate activities in our study since they were not identified as significant activities by the pharmacists during the pre-orientation visits. This could be an area which should be developed further by the hospital pharmacists locally.

Evidence from our study indicates that pharmacists find themselves performing activities that are not necessarily clinical tasks. For optimal utilisation of pharmacist expertise, administrative tasks should take up a minimum of the pharmacist's time and clinical tasks should be performed as efficiently as possible. Yet, although it is important for hospital pharmacists to allocate most of their time to clinical activities, the administrative activities cannot be completely abolished. Within the administrative activities, issues relating to availability and accessibility of medicines are handled and such information is important if pharmacists are to contribute fully to individual patient care at the clinical level.

\section{Conclusions}

This time and motion study indicated that pharmacists' time is mainly allocated to clinical pharmacy activities. However, there is still a large proportion of time taken up by administrative activities which can be conducted by nonpharmacist personnel such as trained pharmacy technicians, allowing more time to be directed to patient care.

\section{Declarations}

\section{Conflict of interest}

The Author(s) declare(s) that they have no conflicts of interest to disclose.

\section{Funding}

This research received no specific grant from any funding agency in the public, commercial or not-for-profit sectors. 


\section{Acknowledgment}

The authors acknowledge the assistance of ${ }^{\mathrm{a}} \mathrm{Ms}$ Maria Mamo, undergraduate pharmacy student, with data collection, and Dr Liberato Camilleri, Lecturer at the Department of Statistics and Operations Research, University of Malta, with statistical analysis.

\section{References}

1. Barber ND et al. Does a high workload decrease ward pharmacists clinical monitoring? Int J Pharm Pract 1993; 2: 153-155.

2. Montazeri M, Cook DJ. Impact of a clinical pharmacist in a multidisciplinary intensive care unit. Crit Care Med 1994; 6: 1044-1048.

3. Robinson NL, Stump LS. Benchmarking the allocation of pharmacists' time-Management Consultation. Am J Health-Syst Pharm 1999; 56: 516-518.
4. Stuchbery $\mathrm{P}$ et al. Identification by observation of clinical pharmacists' activities in a hospital inpatient setting. Pharm Pract 2007; 5: 10-16. www.pharmacypractice.org/vol05/pdf/ 010-016-en.pdf (accessed 6 April 2009).

5. Finkler SA et al. A comparison of work-sampling and time-andmotion techniques for studies in health services research. Health Serv Res 1993; 28: 577-597. www.pubmedcentral.nih.gov/picrender. fcgi?artid=1069965\&blobtype=pdf (accessed 6 April 2009).

6. Emmerton L, Jefferson K. Work sampling observations of community pharmacists: a review. Int J Pharm Pract 1996; 4: 75-78.

7. Rutter PM et al. Pharmacy research: the place of work measurement. Int J Pharm Pract 1998; 6: 46-58.

8. Azzopardi LM. Validation Instruments for Community Pharmacy: Pharmaceutical Care for the Third Millennium. Binghamton, NY: Pharmaceutical Products Press, 2000.

9. Lanzon AM. Time Management in Pharmacy. Dissertation, University of Malta, 2002.

10. Rutter PM et al. Validation of a subjective evaluation study using work sampling. J Soc Admin Pharm 1999; 16: 174-185. 